Revista Mídia e Cotidiano ISSN: 2178-602X

Artigo Seção Traduções

Volume 15, Número 3, set./dez. de 2021

Submetido em: 30/06/2021

Aprovado em: 02/09/2021

\title{
Sobre fake news e fake History
}

\section{Offake news and fake History}

\author{
De las fake news y la fake History
}

\author{
Rosali Fernandez de SOUZA ${ }^{1}$ \\ Rodrigo Aldeia DUARTE ${ }^{2}$
}

\begin{abstract}
Resumo
Este trabalho apresenta a tradução para o português de uma compilação de palestras do professor Jason Steinhauer sobre o tema das fake news e seu correlato, a fake History, conceito criado pelo autor para dar conta da força com que o obscurantismo tem atingido e moldado a visão sobre o passado e a competência em História do público em geral. $\mathrm{O}$ artigo analisa correlações entre as duas questões, que enfraquecem sobremaneira a capacidade do público de distinguir informações falsas das reais, e propõe uma estratégia comunicacional proativa por parte dos historiadores, a comunicação histórica, elemento vital para o combate ao discurso falseador e anticientífico presente nos principais meios de divulgação - especialmente nas novas tecnologias, portais de notícias e mídias sociais - que associa acriticamente História e passado.
\end{abstract}

Palavras-chave: Fake News. Fake History. Comunicação em História. Competência em História. Competência em informação.

\begin{abstract}
This paper presents the Portuguese translation of a compilation of lectures by Professor Jason Steinhauer on the topic of fake news and its correlate, fake History, a concept coined by the author, to account for the strength with which obscurantism has striken and shaped the view on the past and the competence in History of the general public. The article analyzes correlations between the two issues that greatly weaken the public's ability to distinguish false from real information, and proposes a proactive communicative strategy on the part of historians, History Communication, a vital element to fighting the falsifying and unscientific discourse present in today's main means of diffusion -

\footnotetext{
${ }^{1}$ Doutora em Ciêencia da Informação pela Polytechnic of North London. Pesquisadora titular do Instituto Brasileiro de Informação em Ciência e Tecnologia - IBICT / MCTI. Professora do Programa de Pósgraduação em Ciência da Informação IBICT-UFRJ. E-mail: rosali@ibict.br. ORCID: 0000-0002-08907999.

${ }^{2}$ Servidor do Arquivo Nacional. Doutorando do Programa de Pós-graduação em Ciência da Informação IBICT-UFRJ.E-mail: rodrigoduarte@an.gov.br. ORCID: 0000-0003-1239-3799.
} 
especially in new technologies, news websites and social media - that uncritically associates History with the past.

Keywords: Fake News. Fake History. History Communication. History Literacy. Information Literacy.

\section{Resumen}

Este artículo presenta la traducción al portugués de una recopilación de conferencias del profesor Jason Steinhauer sobre el tema de las fake news y su correlato, la fake History, un concepto creado por el autor para dar cuenta de la fuerza con la que el oscurantismo ha afectado y moldeado la visión del público en general sobre el pasado y la literacia en Historia. El artículo analiza las correlaciones entre ambas cuestiones, que debilitan enormemente la capacidad del público para distinguir la información falsa de la real, y propone una estrategia de comunicación proactiva por parte de los historiadores, la comunicación en Historia, elemento vital para combatir el discurso distorsionador y acientífico presente en los principales medios de difusión - especialmente en las nuevas tecnologías, los portales de noticias y las redes sociales - que asocia acríticamente la Historia y el pasado.

Palabras clave: Fake News. Fake History. Comunicación en História. Literacia en História. Literacia en Información.

\section{Introdução}

O presente artigo traz a tradução da compilação de palestras proferidas pelo professor Jason Steinhauer em 2017 a convite da embaixada dos Estados Unidos na Lituânia, sob o título de Of fake news and fake History, publicadas originalmente pelo Foreign Policy Research Institute. Steinhauer é membro fundador do Centro Lepage para História de Interesse Público, da Universidade Villanova, no estado da Pensilvânia. O Centro Lepage "baseia-se na crença que a pesquisa em História e a perspectiva histórica, quando utilizadas para avaliar questões globais contemporâneas, pode nos auxiliar a tomar melhores decisões e criar uma sociedade melhor" (VILLANOVA UNIVERSITY, 2020). O trabalho de Steinhauer é focado no papel da História e do conhecimento histórico na vida pública. Desde 2014 vem defendendo a noção de comunicação histórica e advogando pela formação de comunicadores históricos, que seriam profissionais responsáveis pela comunicação e divulgação da produção acadêmica da área de História para um público não-especializado no complexo ambiente atual dos meios de comunicação e da veiculação de conteúdo. 
Apesar de seu foco específico nas transformações tecnológicas e em seu impacto na divulgação e recepção das informações - e na legitimidade de seus produtores, o artigo permite traçar elos com o conceito de regime de informação, de Bernd Frohmann e com posteriores desenvolvimentos de Maria Nélida González de Gómez. González de Gómez trata o regime de informação como uma ampla "morfologia de rede" (GONZÁLEZ DE GÓMEZ, 2002, p. 34), caracterizada como "modo informacional dominante em uma formação social, o qual define quem são os sujeitos, as organizações, as regras e as autoridades informacionais" (GONZÁLEZ DE GÓMEZ, 2012, p. 43). Frohmann, por sua vez, fala do regime de informação como o fluxo de informações organizado em rede através de canais determinados, produtores específicos, por meio de estruturas organizacionais específicas e voltado a consumidores específicos (FROHMANN, 1995, p. 4). Frohmann salienta ainda que o principal objetivo da pesquisa em política informacional é a acurada representação de regimes de informação (FROHMANN, 1995, p. 5), e ressalta mais à frente que o estudo da informação e da política de informação é fazer intervenções sociais relevantes e inteligentes sobre o exercício de poder e controle sobre a informação (FROHMANN, 1995, p. 11).

Mais do que um fenômeno recente e surpreendente, o autor sugere que as fake news são afiliadas a uma tendência já presente na história dos meios de comunicação, de manipulação de informação para atender interesses determinados. Essas ações de manipulação da informação teriam sido bastante amplificadas e adquirido características específicas no atual regime de informação em virtude do estágio de desenvolvimento das tecnologias de informação e comunicação. Deste modo, a urgência e força atuais da questão das fake news seriam então fruto das modificações e do desenvolvimento tecnológico em curso, que, por meio das profundas transformações recentes que configuram o atual regime de informação e a maneira com que lidamos com o conteúdo informacional disponível, engendram uma verdadeira guerra entre os meios de comunicação tradicionais e os emergentes arranjos produtivos que se colocam como novos atores na disputa de narrativas e do monopólio da legitimidade informacional. As narrativas sobre a realidade (e também sobre o passado) constituem identidades e modos de compreensão, e a atual disputa discursiva, que é também uma disputa de território e mercado dentro do novo contexto tecnológico e informacional, constituem-se como 
marcos de suma importância para entender o quadro presente, em que vicejam visões anticientíficas (como terraplanismo, criacionismo e revisionismo histórico) em detrimento do avanço da ciência e do debate acadêmico qualificado.

Para além da desinformação e manipulação política inerentes às fake news, Steinhauer identifica um processo de mistificação do passado e de perda de espaço do discurso histórico acadêmico no debate público como consequência do atual estágio de desenvolvimento tecnológico e da nova lógica comunicacional e discursiva. À emergência deste novo cenário informacional que associa passado e História sem um debate crítico e que utiliza a legitimidade da palavra história para autorizar discursos falseados sobre o passado e, desse modo, influir na construção de identidades, o autor dá o nome de fake History (conceito cunhado por Jason Steinhauer e aqui mantido em sua forma original para manter o paralelismo com fake news utilizado no título do texto).

A discussão proposta neste artigo é extremamente relevante neste atual momento de prevalência de fake news nas mídias sociais e de revisionismo histórico que desinforma o público em geral (como as diversas posições que consideram o nazismo como uma doutrina de esquerda) e revitaliza regimes de exceção (como a atual onda de revalorização da ditadura civil-militar brasileira de 1964), dando ensejo a reinterpretações do passado baseadas mais em preceitos político-ideológicos que em pesquisa científica e argumentos solidamente embasados.

O trabalho de Steinhauer fala também em historical literacy, aqui traduzida como "competência em História". Desse modo, estabelece um diálogo direto com o conceito de competência em informação, amplamente utilizado no campo da Ciência da Informação, cujo surgimento está relacionado com o forte crescimento na produção e coleta de informações a partir de meados do século XX, e da necessidade de gerir, organizar e comunicar essa informação de forma eficiente, tanto entre os próprios órgãos produtores e acumuladores de informações quanto para o público em geral, especializado ou não. A necessidade de melhor organização da informação, a percepção de seu valor intrínseco e organizacional, num contexto de uma emergente era da informação e a identificada falta de capacidades específicas de pesquisa e seleção de informações na população adulta em geral, gerou programas de orientação bibliográfica e iniciativas de educação em bibliotecas, que começavam a ser encaradas como espaços de disseminação 
do conhecimento, unidades essenciais de provimento de recursos informacionais para a ciência, e elementos fundamentais dos recentes sistemas nacionais de informação em evolução (DUDZIAK, 2016, p. 24). O excesso de informação produzida e a cada vez maior capacidade tecnológica de apresentá-la em diferentes suportes (impresso, microfilmado, eletrônico), exigia maior capacidade de avaliação da informação e habilidades específicas para lidar com a tecnologia e os meios de apresentação da informação (DUDZIAK, 2016, p. 27). O início de uma iminente revolução informacional e o desenvolvimento tecnológico, que nos empurrava mais e mais em direção a uma nova sociedade de informação, a um novo regime de informação dominante, demonstraram a premência de capacidades específicas para a busca, seleção e uso de informações. O conceito de competência em informação pode ser entendido como "conjunto de conhecimentos, habilidades e atitudes direcionado pela necessidade de informação" (DUDZIAK, 2016, p. 36). Nesse sentido, o foco aplicado por Steinhauer com relação à produção de conhecimento em História, a competência em História, seria esse mesmo conjunto de conhecimentos, habilidades e atitudes em função da atenção a necessidades de informação em História. Assim, a competência em História seria uma categoria particular da competência em informação, especificamente a informação de valor histórico ou caráter historiográfico.

O novo papel do historiador inserido no atual regime de informação, o comunicador histórico, segundo o autor, deve ser o de estimular e desenvolver a competência em História no conjunto da sociedade, para além do domínio do público especializado, por meio de uma comunicação ágil e estratégica, com vistas a enfrentar a fake History. Porém a capacidade de avaliar a verossimilhança de informações relativas ao passado exige, além de competência formal na leitura e compreensão da informação, bem como no manejo das tecnologias específicas para o acesso e compartilhamento, uma postura crítica de análise. Compreender a informação em seus distintos contextos (sociais, culturais, econômicos, políticos, etc.), mas também as relações de poder e dominação inerentes às práticas informacionais, seja em seu nível semântico, do conteúdo, seja na arquitetura utilizada pelos distintos sistemas e algoritmos que processam e disponibilizam informação, compreendidas no contexto do regime de informação atual. Nesse sentido, a competência em História e a ação dos comunicadores históricos de Steinhauer aproxima- 
se mais da noção de competência crítica em informação, que reforçaria tanto a urgência de "práticas menos mecânicas e entendimentos mais centrados no indivíduo" quanto de "adoção de uma perspectiva "crítica" às práticas correntes da competência em informação (BEZERRA, 2019, p. 56-57). A competência crítica em informação seria assim uma "ampliação do conceito e do papel social da competência em informação" (BEZERRA, 2019, p. 59), em sentido semelhante ao que o autor defende quando fala em competência em História.

Apresentamos a seguir a tradução do texto Of fake news and fake History, de Jason Steinhauer. As citações feitas no texto original foram traduzidas em conjunto com o restante do texto e mantidas no formato utilizado pelo autor. As palavras em negrito representam destaques feitos pelo autor no texto original. Optamos por não traduzir as expressões fake news e fake History por entender que a primeira já está incorporada ao português como conceito, e para manter um paralelismo entre as duas.

\section{Sobre fake news e fake History: a crise das fake news}

Parece que estamos em meio a uma crise de informação - ou melhor, uma crise de desinformação. A epidemia foi apelidada de "fake news", um termo inicialmente cunhado pelos meios de comunicação para descrever artigos publicados na internet por sites de integridade questionável. O termo foi então voltado contra a própria mídia, pelo menos nos EUA, pelo conservadorismo político instituído - incluindo o atual ${ }^{3}$ presidente Donald Trump que sustenta acusações de "imprensa tradicional de fake news" contra empresas como CNN, Washington Post, New York Times, entre outros. Agora temos uma constante ida e vinda na esfera pública: a mídia tradicional acusa os noticiários online de ser falsos, e os políticos, a seu turno, acusam a mídia de ser falsa.

Para a mídia, o termo fake news é um conveniente espantalho para uma indústria agarrando-se ao próprio futuro. De janeiro de 2001 a setembro de $2016^{4}$, a indústria de jornais impressos dos EUA perdeu mais da metade de seus empregados, de 412000 para 174000. Em contraste, o emprego em portais de publicações e busca na internet subiu de

3 Donald Trump ainda era presidente dos EUA no momento da publicação do texto original.

4 Conforme https://www.bls.gov/opub/ted/2017/newspaper-publishers-lose-over-half-their-employmentfrom-january-2001-to-september-2016.htm. 
67000 em janeiro de 2007 para 206000 em setembro de 2016. Como defender a própria existência se a tecnologia pode estar tornando-a obsoleta? Proclamando-se que os competidores são "fake" - sem credibilidade, não confiáveis, inferiores - e clamando para si o título de "reais": autênticos, veneráveis, defensores de normas e valores institucionais. Mark Thompson, presidente e CEO do The New York Times Company, apresentou essa argumentação no Clube Econômico de Detroit em dezembro de 2016. O tema de sua apresentação era fake news. Sua solução? Assinar o Times, Washington Post, Wall Street Journal, e outros. "Se o cidadão é preocupado com fake news, que ponha o dinheiro onde sua boca está e pague pelo produto autêntico", ele concluiu 5

A preocupação da imprensa norte-americana com fake news é, em parte, manifestação de uma ansiedade dos editores da imprensa tradicional na batalha contra a influência de Facebook, Google, Twitter e outros portais de notícia online. Sempre houve fake news, muito antes dos jornais modernos nascerem, e continuará existindo fake news mesmo após seu fim. Assinar o New York Times, por si mesmo, não resolverá o problema. Em 1807 o presidente norte-americano Thomas Jefferson reclamou ${ }^{6}$ sobre a veracidade dos jornais numa carta para John Norvell, afirmando que "Não se pode acreditar em nada que se vê em um jornal” e que "o homem que nunca olha um jornal é mais bem informado que aquele que os lê". Isso nos lembra que na época de Jefferson os jornais dos EUA não tinham pretensão de ser objetivos: ao contrário, eram porta-vozes de interesses políticos e, na verdade, jornais partidarizados que auxiliaram Jefferson a vencer a presidência sobre John Adams em 1800 - frequentemente utilizando práticas que Jefferson posteriormente condenaria. Nos anos 1830, houve um famoso "boato lunar", do jornal New York Sun, que afirmara ter evidências da vida na lua. Esse foi, talvez, o epítome das fake news. Apesar disso, ajudava a vender jornais. E aqueles que conhecem a guerra Hispanoamericana sabem que os jornais norte-americanos da época estavam recheados de relatos falsos de crueldade espanhola em Cuba, sem mencionar reportagens enganosas sobre a explosão do navio USS Maine. Suas reportagens ajudaram a impulsionar os EUA à guerra contra a Espanha. Mesmo antes dos jornais, em sociedades em que o letramento não era

5 Conforme https://www.nytco.com/press/mark-thompson-delivers-speech-on-fake-news/. 6 Conforme https://press-pubs.uchicago.edu/founders/documents/amendI_speechs29.html. 
amplamente disseminado, desinformação, informação falsa e "fake news" circulavam por rumores, histórias orais, canções, cartas, panfletos, imagens e relatos ${ }^{7}$. Nos EUA, as fake news não estão confinadas apenas ao mundo gráfico; por uma geração, programas de rádio e televisão espalharam teorias da conspiração e informações de integridade questionável, tanto que ajudaram a criar um gênero satírico de "fake news" dando origem a formatos como os de The Onion, The Daily Show e The Colbert Report. Informação falsa, disseminada para alcançar objetivos políticos, ideológicos, financeiros ou humorísticos não é novidade e irá continuar a despeito do meio de comunicação utilizado.

A crise de nossa geração com as fake news é uma questão tecnológica semelhante à maneira como a imprensa, os tabloides, o rádio e a televisão alteraram o cenário informacional antes de nós. Nossa tecnologia é a internet, e é a penetração, viralidade e velocidade da Rede Mundial de Computadores (World Wide Web) que engendrou nossa urgência sobre as fake news hoje em dia. A rede e as mídias sociais são ferramentas poderosas que podem espalhar fake news por todo planeta em um instante. Elas também podem espalhar os fatos que as refutam. Como qualquer ferramenta, o desafio é garantir que se possa educar as pessoas que a utilizam, mesmo durante o aperfeiçoamento da própria ferramenta. Em 2016, o Grupo de Educação Histórica de Stanford publicou uma pesquisa de 18 meses com mais de 7000 estudantes norteamericanos que revelou que a capacidade dos alunos de raciocinar sobre a informação da internet é desoladora. Os estudantes não conseguiram distinguir uma matéria de um jornalista de uma peça publicitária, e, de modo geral, não tomam tempo para investigar se um site ou uma conta de mídia social tem inclinações ou interesses ocultos. A questão, parece, é menos o que fazer sobre as fake news, e mais o que fazer com cidadãos que não possuem os instrumentos ou habilidades para reconhecê-las - ou pior, preferem-nas porque se alinham ou reforçam seus pontos de vista. Para citar o filósofo Michael Lynch, a internet é "tanto o melhor verificador de fatos do mundo quanto o maior reafirmador de preconceitos do mundo - frequentemente ao mesmo tempo".

7 Ver, por exemplo, Krisna Ruette-Orihuela \& Cristina Soriano, "Remembering the Slave Rebellion of Coro: Historical Memory and Politics in Venezuela," Ethnohistory 63:2 (Abril 2016) doi 10.1215/00141801-3455331. 
Fake history: A crise menos conhecida

As consequências das fake news são muito reais. Informações imprecisas ou propositadamente enganosas nos meios de comunicação têm o poder de influenciar nossa política, nossos governos e as políticas que criamos para o futuro. No longo prazo, contudo, é a informação sobre o passado que tem o poder para moldar nossas identidades, nossas nações, nossas instituições e nossas opiniões sobre outros. Todo zelo para combater as "fake news" tem que ser complementado com um igual - senão maior - zelo para enfrentar a "fake History". "Fake History" é um fenômeno de longo prazo que tem emergido ante nossos olhos. E de modo distinto de como as "notícias reais" contrapõemse às "fake news" todo dia na esfera pública, a "história real" que se contrapõem à "fake History" desapareceu gradualmente da vista do público.

Para destacar esta discussão, gostaria de relembrar um artigo opinativo do colunista do New York Times Nicholas Kristof em fevereiro de 2014. No artigo intitulado "Professors, We Need You!"8, Kristof lamentava que os acadêmicos são largamente invisíveis na esfera pública. Sua invisibilidade não é, segundo Kristof, um problema para os próprios acadêmicos. É um problema para os EUA. Para Kristof, os EUA - as instâncias decisórias do Estado e a nação em sentido mais amplo - necessitam das mentes acadêmicas para formulação de políticas sensatas e ajudar a resolver problemas sociais urgentes. Ao confinar sua sabedoria aos periódicos científicos e enterrar suas ideias sob um linguajar inacessível, os intelectuais fizeram um desserviço a si mesmos, ao planejamento de políticas públicas e ao povo norteamericano. A sociedade teria muito a enriquecer-se com a contribuição das melhores mentes do país lidando com as questões mais iminentes da nação.

A coluna de Kristof tornou público um sentimento que vem crescendo há bastante tempo na última geração: notadamente que a academia tornou-se tão especializada e cheia de jargões que deixou de ter real conexão com o mundo. A História acadêmica não é uma exceção. Ao longo de uma geração, os historiadores deslocaram-se para a hiperespecialização, pesquisando assuntos de limitado (ou nenhum) atrativo para

8 Conforme https://www.nytimes.com/2014/02/16/opinion/sunday/kristof-professors-we-needyou.html?_r=0. 
o público; e consumidos por revisões por pares e provas de títulos às expensas do interesse público. Não coincidentemente, a produção acadêmica de história praticamente desapareceu da esfera pública. Os historiadores publicam fervorosamente, mas cada vez menos público não especializado está lendo. A média de vendas de uma monografia acadêmica é atualmente estimada em algumas centenas de cópias ${ }^{9}$ — no melhor dos $\operatorname{casos}^{10}$. Um estudo de 2014 chegou à conclusão que em média um artigo acadêmico era lido integralmente por 10 pessoas. Quase 1,5 milhões de artigos revisado por pares são publicados anualmente - 82 por cento dos de humanidades não são citados nenhuma vez. Ninguém faz referência a 32 por cento dos artigos revisados por pares em ciências sociais. Por mais brilhante que seja a pesquisa acadêmica, sua visibilidade e influência no mundo afora é, infelizmente, quase sempre mínima ${ }^{11}$.

Uma decorrência dessa retração é uma indiscriminada escassez de "competência em História" na sociedade. Eu evito falar em "perda" de competência em História porque não estou convencido que nós nos EUA já tenhamos tido muito disso no passado, nem estou preparado para dizer que o nível atual de competência em História nos EUA é menor que o de gerações anteriores. Mas do mesmo modo que a imprensa escrita está em estado de ansiedade em relação aos padrões que está lutando para manter, também a História está num estado semelhante. Os norte-americanos simplesmente não sabem - ou não se esforçam para reconhecer - "boa" História da "ruim", pesquisa acadêmica séria de mitos populares. Como resultado, o que queremos dizer com a palavra "História", o que a palavra significa, o que ela abrange, o que se apresenta como História, e, de maneira mais crítica, como ela é comunicada, todos esses elementos estão movendo-se rapidamente sob nossos pés. O que a História passou a significar desde sua organização como profissão na segunda metade do século XIX - uma disciplina interessada no criterioso uso de evidências para tecer comentários interpretativos sobre o passado - está evoluindo ante nossos olhos.

9 Conforme https://academicmatters.ca/reflections-on-university-press-publishing/.

10 Harnum afirma que as vendas por monografia estavam entre 300 e 400 cópias em 2007; estima-se que sejam ainda menores hoje.

11 Estatísticas tiradas de "Prof, no one is reading you," The Strait Times, 11 de abril de 2015. Acesso em 2 de junho de 2015. Disponível em: https:/www.straitstimes.com/news/opinion/more-opinionstories/story/prof-no-one-reading-you-20150411. 
Para entender isso é necessário que façamos a distinção entre o passado e a História. O passado compreende o infinito número de eventos que ocorreram antes do momento atual. Ao ler essa frase, estamos no presente. E agora? A leitura daquela frase anterior está no passado. O passado - o que os humanos fizeram até este momento continua um tópico de infinito interesse para os seres humanos. O problema é que passado e história, apesar de não serem sinônimos, são usados de modo intercambiável nos EUA de hoje. A História lida com a interpretação de coisas que ocorreram no passado. Mais precisamente, a História lida com a interpretação de coisas que de fato aconteceram. Historiadores chamam essas coisas de fatos. Os historiadores comprovam os fatos com evidências: documentos ou outros elementos que provam com alguma certeza que eventos de fato ocorreram. A História tem interesse em evidências: apresentá-las e explicá-las. E eis onde surge o obstáculo. Pois nem todos irão olhar os fatos e evidências e propor a mesma explicação sobre como e porque uma coisa aconteceu da maneira que aconteceu. Historiadores no futuro podem achar cópias de meus escritos e usá-las como evidência para sugerir que, de fato, durante minha vida, eu escrevi sobre História. Mas esses historiadores do futuro podem discordar sobre a razão pela qual eu escrevia. Alguns podem considerar a hipótese que foi minha carreira na Biblioteca do Congresso que me motivou. Outros podem dizer que, na verdade, foi a experiência de minha família no Holocausto. Cada um desses argumentos estaria baseado em evidências, e ofereceria uma interpretação do fato de minha escrita no contexto maior de minha vida e do mundo à minha volta. Assim, como escreveu John Arnold, “A História é acima de tudo um debate. Debates são importantes, eles criam a possibilidade de modificar as coisas" ${ }^{12}$. Como a História lida com interpretações de eventos passados balizados em evidências - e como novos eventos estão sempre acontecendo e novas evidências são sempre encontradas - a História é um debate contínuo e dinâmico que busca compreender a infinidade de ações humanas que ocorreram antes do momento atual e tiveram um efeito determinante em nossa situação de hoje. Apesar de ambos terem seu valor e serem interessantes, a História é bem mais que uma mera narrativa sobre o que aconteceu no passado.

12 John H. Arnold. History A Very Short Introduction. Oxford University Press (Oxford: 2000), p.13. 
Eu sugeriria que muitos norte-americanos não conseguem diferenciar passado e História. Isso é evidente na televisão, na qual temos nos EUA um canal de História cuja programação agora inclui "Pawn Stars", "Swamp People", "Counting Cars", "Ax Men" e "The Marijuana Revolution"13. Uma porção significativa da programação do History Channel é, em verdade, histórias de pessoas que vivem no presente, e há muito pouca interpretação baseada em evidências. Na rede, existem contas de mídias sociais como @HistoryInPics que ostenta mais de 4 milhões de seguidores ${ }^{14}$. @ HistoryInPics publica fotos tiradas no passado sem interpretação, com legendas muitas vezes informais e nem sempre baseadas em evidências, e em algumas oportunidades imagens que são verdadeiramente ficcionais, e portanto não são história porque não representam interpretações de eventos que tenham de fato acontecido ${ }^{15}$. Nossos navegadores têm uma ferramenta de "histórico de navegação", que é simplesmente uma lista de sites que visitamos no passado (isso pode parecer uma crônica, definida pelo Dicionário Webster como descrição de eventos na ordem em que ocorreram, mas na realidade lembra mais o que chamamos de lista). Nossas contas de Gmail têm uma função "arquivo" - mas um arquivo funciona conforme práticas bem estabelecidas de integridade arquivística e é organizado e descrito segundo rígidos padrões arquivísticos. O Arquivo Nacional dos EUA descarta mais de 90 por cento do material que coleta, enquanto o Gmail, contraditoriamente, afirma que seus usuários jamais terão que apagar qualquer coisa. A função "arquivo" do Gmail é na verdade o oposto de arquivamento de muitas maneiras. A função "arquivo" seria melhor nomeada como "mover" - i. e. você move seus e-mails de um espaço de armazenamento virtual para outro.

Há razões para que os navegadores usem o termo "história", para que o Gmail use o termo "arquivo", e por que o @HistoryinPics não tenha escolhido o nome @ThePastInPics. Existe uma razão pela qual os famosos escritores norte-americanos David McCullogh (jornalista de formação), Michael Beschloss (que tem um título em negócios por Harvard) e Doris Kearns Goodwin (uma ex-agente do governo norte-

13 Séries e filmes veiculados no canal History Channel 14 Contagem de seguidores em 19 de junho de 2017. Fonte: https://www.Twitter.com/HistoryInPics. 15 Um exemplo: @HistoryInPics publicou uma foto de John Lennon tocando violão com Che Guevara. Não existe indício que os dois tenham se conhecido, e foi confirmado que a fotografia foi manipulada. 
americano) chamam a si mesmos de historiadores e não, simplesmente, escritores. É porque a terminologia de História carrega conotações de autoridade, credibilidade e reverência. Mesmo assim, ironicamente muito do que envolve o passado na cultura convencional norte-americana não seria considerado histórico - pelo menos não no sentido que a profissão de historiador define. Não coincidentemente, pouco do que envolve o passado na cultura convencional envolve os historiadores. Mesmo que o trabalho de um historiador encontre visibilidade pública, em geral não é o historiador a pessoa celebrada por isso. Normalmente é um jornalista ou dramaturgo que guia a conversa - alguém que tenha uma plataforma pública, acesso a uma audiência, e credibilidade comunicativa com sua audiência. Celebridades da mídia como Glenn Beck e Bill O’Reilly têm livros de história campeões de venda, que em muito superam aqueles escritos por historiadores acadêmicos ${ }^{16}$. Empresas da lista Fortune 500 usam fotografias antigas - algumas em domínio público, outras não - visando manipular as interações na rede, aumentar os acessos e maximizar os dólares gastos em propaganda. Governos e mandatários classificam suas políticas como sendo "históricas" numa maneira de précertificar sua relevância duradoura. A História está aparentemente em todo lugar e em lugar algum. Essa é a "História" hoje em dia nos EUA. Consequentemente, não deveria ser surpresa que muitos norte-americanos não tenham a habilidade de distinguir a História boa da ruim.

\section{Comunicação em História}

A História - a interpretação analítica do passado baseada em avaliações críticas de evidências - está sendo transformada por nossa revolução das comunicações. Num mundo em que recebemos a maior parte das informações de meios visuais como a web, a televisão, e aparelhos de telefonia móvel - e no qual cedemos aos criadores e usuários dessas plataformas a autoridade para ditar aquilo que devemos ou não dar atenção - o que passa por História é, no mais das vezes, fragmentos de informação sobre o passado difundidos na web, tirados de contexto, desprovidos de análise, e direcionados a

16 Esta observação foi apontada no encontro anual de 2015 em New York da Associação Histórica e repetida no mesmo encontro em 2016. Para fontes, ver a listagem do Bookscan dos maiores best-sellers de História de 2014. A lista inclui também Howard Schultz, CEO da Starbucks. 
promover interesses políticos, ideológicos, financeiros ou pessoais. Do mesmo modo que esse ambiente teve um efeito transformador naquilo que se convencionou chamar jornalismo e notícia, também teve um efeito transformador naquilo que se convencionou chamar História. Ele cria as condições para a "fake History" crescer. Se os historiadores quiserem reivindicar a definição de História e incutir competência em História em nossas populações, terão que vagar brava e confiantemente por este complexo ambiente de comunicação. Muitos já estão fazendo isso, tentando resgatar a História real da fake History do mesmo modo que jornalistas estão tentando resgatar notícias reais das fake news.

Combater essa situação não será fácil e irá demandar uma estratégia de múltiplas vertentes. Muitas das estratégias utilizadas para identificar e sinalizar matérias com fake news também podem ser efetivas para identificar fake History. Quase todas essas estratégias estão sendo dirigidas por profissionais de tecnologia; empresas como Google e Facebook, ou vigilantes como os Baltic elves ${ }^{17}$ identificam desinformação na rede e a refutam - uma abordagem reativa. Mas os historiadores e intelectuais também têm um papel: uma abordagem proativa. Temos que saturar a televisão, a web e mídias sociais com História real e trabalho acadêmico honesto. Não é suficiente para historiadores escrever uma monografia de 400 páginas e confiar que representantes eleitos e demais cidadãos a lerão. Os historiadores precisam adaptar-se aos deslocamentos sísmicos na comunicação e às novas formas pelas quais as pessoas comunicam-se via TV, web e dispositivos móveis. Os historiadores precisam reconquistar quotas no mercado de ideias e no mercado da atenção do público - e para fazê-lo será necessário modificar como e onde comunicamos nossa produção intelectual, ao mesmo tempo que replicarmos nosso conhecimento através de múltiplos meios e liberando-o das barreiras econômicas do acesso pago. Numa era em que constantes demandas colocam-se sobre o tempo, as mentes e os globos oculares das pessoas, as regras de mercado infelizmente aplicam-se à História. E historiadores acadêmicos têm uma porcentagem muito pequena da fatia do mercado de informação nos EUA. Wikipedia, Google, Glenn Beck, Michael Beschloss e

17 Nome pelo qual são conhecidos os grupos de voluntários de países bálticos que se dedicam a combater propaganda e fake news de suposta origem russa na web (Nota dos Tradutores). 
@HistoryInPics têm mais - e tomados em conjunto têm consideravelmente mais. Para reconquistar as quotas, os historiadores devem comunicar conteúdo de maneira apropriada ao meio e que dialogue com audiências além da academia. Mais significativamente, toda uma geração de nativos digitais necessita que lhes seja demonstrado de que consiste a boa História. É preciso mostrar a eles que o conhecimento bom e honesto, que interpreta criticamente os eventos passados, vale seu tempo e atenção - e que se ocupar deste material os fará mais espertos, mais bem informados e mais aptos a tornar o mundo melhor. Tal é a espantosa tarefa com que se deparam agora os historiadores.

Como a História é comunicada terá um efeito determinante sobre o futuro da profissão. Por mais que nós historiadores valorizemos as monografias e artigos científicos, também teremos que adotar vídeos na web, listas, conhecimento colaborativo, GIFs, memes, podcasts, blogs, mídias sociais, imagens, emojis e mais - e incentivar e premiar historiadores por usarem esses meios. Por esta razão, eu e outros propusemos que a História necessita de comunicadores em História, e criamos o campo da Comunicação em História. Da mesma forma que a ciência tem comunicadores em Ciência, os comunicadores em História, como seus equivalentes da área científica, são historiadores que vão além dos muros das universidades e instituições para participar de debates públicos; envolvem-se em conversas com formuladores de políticas públicas e com o público; comunicam a História num tom envolvente que desperte interesse massivo transversalmente, seja em meio impresso, vídeo ou áudio; e militam por decisões políticas instruídas por pesquisa histórica. Comunicadores em História ensinam competência em História: a análise crítica das fontes, argumentação e contra argumentação, como avaliar evidências e como provar uma hipótese. Mais importante, comunicadores em História defendem a História contra simplificação, desinformação ou propaganda, e explicam conceitos históricos básicos que nós da profissão tomamos por óbvios. Comunicadores em História são historiadores e comunicadores hábeis. Eles são cativantes. São dinâmicos. Contam histórias, manejam metáforas e analogias de modo eficaz, são sucintos e são capazes de depurar ideias complexas em linguagem acessível. São retóricos habilidosos, brilhantes oradores, e têm a capacidade de conectar-se tanto emocionalmente quanto intelectualmente com as plateias. São hábeis nos modos de persuasão, não 
somente recorrendo à lógica e ao raciocínio, mas também ao caráter, valores e emoções das audiências. São capazes de comunicar-se por diversos meios e têm uma forte presença em mídias sociais. Eles são diversificados, tanto em idade, etnia e aparência. São um tipo de historiador diferente do que a profissão produziu até hoje.

\section{Uma chamada para ação}

Já vimos o que ocorre quando há uma carência generalizada de competência em História numa população. Não é somente que membros do governo e candidatos a cargos políticos falem descuidada e perigosamente sobre o passado, ou que agentes do Estado utilizem falsidades para deliberadamente semear instabilidade numa região. É também o fato de cidadãos terem falta de habilidade, motivação, e autoconfiança intelectual para desembaraçar mito de fato, ideologia de pesquisa honesta. É isso que deve nos compelir a agir. Da mesma forma que as fake news nunca deixarão de existir, a fake History também não vai desaparecer. Autoritários e demagogos continuarão a usar o passado como meio de incitar e dividir a sociedade. Precisamos de História real que confronte essa situação, comunicada ampla, popular e efetivamente - e a sabedoria para poder diferenciar entre os dois.

\section{Considerações finais dos tradutores}

$\mathrm{O}$ artigo do professor Steinhauer toca em questões importantes sobre as fake news e a fake History, em especial sua força no contexto informacional vigente e as possíveis ações para mitigar seus impactos e suas possíveis consequências na estrutura social e nos meandros do debate político. A desinformação, seja sobre questões do presente, seja sobre o discurso sobre o passado, assume cada vez mais um caráter ativista em nome de interesses político-ideológicos pouco afeitos à veracidade e à integridade dos fatos e aos dados de pesquisa disponíveis.

A discussão sobre competência em História, entendida como parte integrante da discussão mais ampla sobre competência em informação, é de fundamental importância para o atual quadro de guerra de narrativas no meio político e social ocasionado pela nova configuração do regime de informação e pela estrutura sociotécnica que se vem construindo a partir do desenvolvimento das tecnologias de informação e comunicação. 
O maior compartilhamento de informações legítimas oriundas de pesquisa criteriosa, o alcance e a visibilidade do discurso acadêmico qualificado e seu impacto no debate público, são fundamentais para uma discussão salutar e honesta sobre os mais variados temas. Porém, esse maior impacto da discussão acadêmica no debate público exige que a produção acadêmica seja melhor comunicada ao público não-especializado. Desse modo, o autor Steinhauer sustenta a necessidade de formação de um novo tipo de profissional no cenário da relação entre a produção acadêmica e a arena pública: o comunicador histórico. Esse novo profissional, parte comunicador parte historiador, armado tanto com a fluidez e as estratégias comunicacionais adequadas à nova realidade dos regimes de informação atuais e da cultura de compartilhamento das mídias sociais, quanto com os elementos argumentativos do discurso acadêmico legítimo, é um agente fundamental na intermediação entre a academia e a sociedade.

No atual cenário brasileiro, em que recentemente o revisionismo histórico vem ganhando tanta força e em que obras de divulgação sem embasamento científico ajudam a moldar a identidade e a competência em História, é forçoso que a academia recupere a legitimidade e a autoridade sobre o discurso histórico, sem, contudo, descuidar da linguagem e das estratégias comunicacionais adequadas à nova realidade informacional. A luta pela valorização da Universidade e da produção científica não pode descuidar das linguagens atuais e da competência em informação (ou em História) do conjunto da sociedade, que vem sendo assolada por informações pseudocientíficas e pseudojornalísticas que assumem cada vez mais caráter de legitimidade. A atual onda orquestrada de desinformação, a serviço de interesses políticos e ideológicos, tem contaminado o debate público de forma avassaladora. Segundo os argumentos de Steinhauer, esta nova e ameaçadora realidade precisa ser duramente combatida na mesma moeda, com uma comunicação ágil, fluida e em consonância com o quadro atual do desenvolvimento tecnológico e do regime de informação. Só assim, na visão do autor, seria possível reagir à epidemia de fake news e fake History que vivemos atualmente.

Em sua chamada para ação, Jason Steinhauer propõe aos historiadores que reassumam o protagonismo perdido para as mídias sociais no discurso sobre as interpretações do passado, entendido como central na questão da identidade e das visões possíveis de alternativas de futuro. O debate social e político, que hoje se encontra 
fortemente preso ao debate sobre a veracidade das informações disponíveis, carece de maior interlocução com o debate científico e acadêmico que deve servir de base e insumo para a formulação de políticas públicas e para a conformação de discursos.

\section{Referências}

BEZERRA, Arthur. Teoria crítica da informação: proposta teórico-metodológica de integração entre os conceitos de regime de informação e competência crítica em informação. In: BEZERRA, Arthur; et al.. iKritica: estudos críticos em informação. Rio de Janeiro: Garamond, 2019, p. 15-72.

DUDZIAK, Elisabeth. Políticas de competência em informação: leitura sobre os primórdios e a visão dos pioneiros da information literacy. In: ALVES, Fernanda; CORRÊA, Elisa; LUCAS, Elaine (orgs.). Competência em informação: políticas públicas, teoria e prática. Salvador: EDUFBA, 2016. p. 19-50.

FOREIGN POLICY RESEARCH INSTITUTE. A Nation Must Think Before it Acts: Of Fake News and Fake History Disponível em: <https://www.fpri.org/article/2017/06/fake-newsfake-history/>. Acesso em: 26 mai. 2020.

FROHMANN, Bernd. Taking information policy beyond information science: applying the actor network theory. In: ANNUAL CONFERENCE CANADIAN ASSOCIATION FOR INFORMATION SCIENCE, 23, 1995, Edmond, Alberta. Proceeddings... Alberta, 1995.

GONZÁLEZ DE GÓMEZ, Maria Nélida. Novos cenários políticos para a informação. Ciência da Informação, v. 31, n. 1, 2002.

GONZÁLEZ DE GÓMEZ, Maria Nélida. Regime de informação: construção de um conceito. Informação \& Sociedade: Estudos, v. 22, n.3, 2012.

VILLANOVA UNIVERSITY. About Villanova University. Disponível em:

<https://www1.villanova.edu/villanova/artsci/lepage/about.html>. Acesso em: 26 mai. 2020. 